\title{
Evaluation of Pure Aluminium Inoculated with Varying Grain Sizes of an Agro-waste based Inoculant
}

\author{
Adeyemi I. Olabisi*, Thankgod E. Boye, Emagbetere Eyere
}

Department of Mechanical Engineering, P. M. B. 1221, Federal University of Petroleum Resources, Effurun, 330102, Nigeria

\begin{tabular}{l} 
A R T I C L E I N F O \\
\hline Article history: \\
Received: 01 March, 2017 \\
Accepted: 07 April, 2017 \\
Online: 13 April, 2017
\end{tabular}

Keywords:

Evaluation

Inoculation

Pure Aluminium

Agro-waste

Grain Size

\begin{abstract}
A B S T R A C T
Pure Aluminium and its alloy are widely utilized in Engineering and Industrial applications due to certain significant properties such as softness, ductility, corrosion resistance, and high electrical conductivity which it possesses. Addition of an agro-waste based grain refiner to the melt can alter the characteristics positively or negatively. Therefore, the aim of this paper is to investigate the inoculating capability of an agro-waste based inoculant and the effect of adding varying sizes of its grains on some of the properties of pure aluminium after solidification. The beneficial outcome of this investigation would enhance the economic value of the selected agro-waste and also broaden the applications of aluminium in Engineering. The assessed properties include; microstructure, micro hardness, ductility, and tensile strength. The agro-waste used as the grain refiner is pulverised cocoa bean shells (CBS). Three sets of test samples were produced using dry sand moulding process, with each melt having a specified grain size of the inoculant added to it (150, 225 and 300microns respectively). Ladle inoculation method was adopted. The cast samples after solidification were machined to obtain various shapes/sizes for the different analysis. The microstructural examination showed that the mechanical properties are dependent on the matrix as the aluminium grains became more refined with increasing grain size of the inoculant. I.e. Due to increasing grain size of the inoculant, the micro hardness increased $(56,61,72 \mathrm{HB})$ as the aluminium crystal size became finer. Meanwhile, the tensile strength $\left(284,251,223 \mathrm{~N} / \mathrm{mm}^{2}\right)$ and ductility $(1.82,0.91,0.45 \% \mathrm{E})$ decreased as grain size of the inoculant increased. The overall results showed that the used agro-waste based inoculant has the capability of refining the crystal size of pure aluminium as its grain size increases. This will make the resulting aluminium alloy applicable in areas where hardness is of superior consideration relative to tensile strength.
\end{abstract}

\section{Introduction}

Through innovative thinking, most of the wastes in our environment which take space, and require huge cost of disposal or pollute our ecosystem as they decompose or when burnt, can be converted for use in the industry to develop improved materials which are indigenous for enhancing cost effective production and customer satisfaction. Consequently, this work focuses on investigating the potential of cocoa beans shell which is one of the

\footnotetext{
*Corresponding Author: Adeyemi I. Olabisi Department of Mechanical Engineering, P. M. B. 1221, Federal University of Petroleum Resources, Effurun, 330102, Nigeria

Email: adeyemi.olabisi@fupre.edu.ng
}

agro-waste in our environment, to be used as indigenous inoculant for improving the microstructure and mechanical properties of pure aluminium.

Pure aluminium is soft, ductile, corrosion resistant and has a high electrical conductivity. It is widely used for foil and conductor cables, but alloying it with other elements is necessary to provide the higher strength needed for other applications. Aluminium is one of the lightest engineering metals, having strength to weight ratio superior to steel. By utilizing various combinations of its advantageous properties such as strength, lightness, corrosion resistance, recyclability and formability, aluminium is being employed in an ever-increasing number of applications. This array 
of products ranges from structural materials to thin packaging foils $[1,2]$.

Pure aluminium does not have a high tensile strength. However, the addition of alloying elements like manganese, silicon, copper and magnesium can increase the strength properties of aluminium and produce an alloy with properties tailored to particular applications [2].

Aluminium is well suited to cold environments. It has the advantage over steel in that its' tensile strength increases with decreasing temperature while retaining its toughness. Steel on the other hand becomes brittle at low temperatures [3].

Inoculation is defined as the addition of a certain solid particles to the molten metal in order to obtain changes in crystals distribution, more uniform microstructure, improvements in mechanical properties, and a reduction of the chilling tendency [4].

The phenomenon of crystallization following after pouring molten metal into the mould, determines the shape of the primary casting (ingot) structure, which significantly has effects on its usable properties. The crystallization of metal in the mould may result in three major structural zones $[2,5]$.

(a) Zone of chilled crystals (grains) formed by equiaxed grains with random crystallographic orientation, which are in the contact area between the metal and the mould.

(b) Zone of columnar crystals (grains) formed by elongated crystals, which are parallel to heat flow and are as a result of directional solidification, which proceeds when thermal gradient on solidification front has a positive value.

(c) Zone of equiaxed crystals (grains) formed by equiaxed grains with random crystallographic orientation in the central part of the casting. The equiaxed crystals have larger size than chilled crystals and are as a result of volumetric solidification, which proceeds when thermal gradient has a negative value in liquid phase.

Depending on the cooling rate, chemical composition and the intensity of convection of solidifying metal in the casting may be three, two or only one structural zone [2].

The tensile strength of wrought aluminium is not high. However, introduction of alloying elements such as silicon, copper, manganese, and magnesium can enhance the strength characteristics of aluminium and make an alloy having properties targeted at particular applications [6].

Thorough literature study revealed that the inoculant (powdered CBS) used for this work has never been used before as a grain refiner for any metal. Common aluminium melt treatment inoculants in use include $\mathrm{MgFeSi}$ [7], Al-Ti-C and Al-3Ti-1B [8], in situ AlN-TiN-TiB2/Al composite inoculants [9]. Addition of some special master alloys that have much particles functioning as the substrates for heterogeneous nucleation can cause the grain size of the inoculated alloys to be noticeably reduced and enhance the comprehensive properties [10 -12]. In reality, majority of the master alloys are linked to Al-based composites, in which the aluminium-based solid solution is the matrix and the inoculant particle is the secondary phase [9].

From literature search, cocoa bean shell was found to contain some already existing inoculant elements as part of its compositions. The overall content of cocoa bean shell [13] and the mineral content $[14,15]$ are as shown below in Table 1 and 2 respectively.

Table 1. Content of Cocoa Bean Shell Powder

\begin{tabular}{|l|c|}
\hline Minerals & $43.18 \%$ \\
\hline Crude fibre & $21.3 \%$ \\
\hline Crude protein & $17.6 \%$ \\
\hline Ether extract & $5.9 \%$ \\
\hline Ash & $9.3 \%$ \\
\hline Total sugar & $1.0 \%$ \\
\hline
\end{tabular}

Table 2. Mineral Content of Cocoa Bean Shell

\begin{tabular}{|l|l|}
\hline Minerals & Value \\
\hline Calcium & $3.7 \mathrm{~g} / \mathrm{kg}$ \\
\hline Phosphorus & $4.4 \mathrm{~g} / \mathrm{kg}$ \\
\hline Potassium & $26.8 \mathrm{~g} / \mathrm{kg}$ \\
\hline Sodium & $0.2 \mathrm{~g} / \mathrm{kg}$ \\
\hline Magnesium & $4.3 \mathrm{~g} / \mathrm{kg}$ \\
\hline Copper & $39 \mathrm{mg} / \mathrm{kg}$ \\
\hline
\end{tabular}

Therefore, the scope of this work is specifically to study the inoculating ability of the selected agro-waste and to investigate the effect of varying the grain size of the inoculant on pure aluminium. The evaluation will be limited to determining the tensile strength, ductility, micro hardness and microstructure of the resulting specimens.

\section{Materials and Method}

\subsection{Materials/Equipment Selection}

The materials selected for this research are cocoa bean shells (CBS), silica sand, water, and pure aluminium having the composition as presented in Table 3. Equipment selected include sieves of aperture $150 \mu \mathrm{m}, 225 \mu \mathrm{m}$, and $300 \mu \mathrm{m}$ respectively, LCD series 2-digits and 3-digits electronic weigh balance, a $40 \mathrm{~kg}$ capacity crucible furnace, three rectangular shaped wooden 
patterns of dimension $300 \mathrm{~mm} \times 40 \mathrm{~mm}$ which were used to make a pair of cope and drag moulds, a stirrer, hack saw, Universal Testing Machine (model- UTE 100, max.capacity-30KN, MakeFuel Instruments \& Engineer's Pvt. Ltd., Maharashtra), Vickers Micro hardness tester (Make-Saroj Udyog Pvt. Ltd., Maharashtra, India), Structure reveal machine (Meji optical microscope Make ZEISS Axiovert 40 MAT, Japan), and Keller enchant. All the workshop and laboratory equipment utilized were assessed at the Federal University of Petroleum Resources, Effurun (FUPRE), and the Petroleum Training Institute (PTI), both are situated in Delta State, Nigeria.

Table 3. Composition of the chosen pure aluminium

\begin{tabular}{|l|l|l|l|l|l|l|}
\hline Alloys & Al & $\mathbf{F e}$ & $\mathbf{S i}$ & $\mathbf{C u}$ & $\mathbf{T i}$ & $\mathbf{M n}$ \\
\hline Composition & 99.9 & 0.03 & 0.04 & 0.01 & 0.01 & 0.01 \\
\hline
\end{tabular}

\subsection{Method/Experimental Procedure}

Dry sand casting method was used to produce the test samples. The agro-waste based inoculant raw material (CBS) was obtained separately (Figure 1), well sun-dried, and cleaned to remove impurities. It was then crushed, and pulverized into a fine powder and sieved using different sieves of 150, 225, and 300microns aperture respectively [16]. The samples were sand cast in the foundry workshop. The aluminium was melted using a 40 $\mathrm{kg}$ capacity crucible furnace pre-heated at $10^{\circ} \mathrm{C}$. Three rectangular shaped wooden patterns of dimension $300 \mathrm{~mm}$ x $40 \mathrm{~mm}$ were used to make a pair of cope and drag moulds. Four moulds were prepared a day before the actual casting from a mixture of dried fresh silica sand, and water. This was done to dry the mould completely in order to reduce casting defects. The four moulds were labeled as sample 1, 2, 3 and 4 respectively. A $15 \mathrm{Kg}$ known quantity of pure aluminium were melted at $720^{\circ} \mathrm{C}$ in the crucible furnace and poured at $700^{\circ} \mathrm{C}$ into the pouring ladle. The first batch of the melt without addition of inoculant was poured into the mould labeled sample 1 . Thereafter, a known quantity (15grams precisely) of the inoculant having grain size of 150 microns (Figure 2) was added to the melt stream and stirred manually with a stirrer in order to facilitate a homogeneous bath and poured into the second mould labeled sample 2. Also, addition of the inoculant having grain sizes of 225 (Figure 3), and 300microns (Figure 4) was done in succession and poured into the third and fourth moulds labeled sample 3 , and 4 respectively. A uniform quantity $(15 \mathrm{~g})$ of the inoculant was used for all samples produced. After, total solidification, the castings were knocked out of the moulds and thoroughly fettled and cleaned before dispatching them for evaluation.

The various test samples were cut or shaped to sizes and taken to the Petroleum training institute metallurgical/microscopic accredited laboratory for micro hardness test, tensile test and Image analyzer test respectively. As shown in the appendix, the samples were machined and measured to fit into the Universal Testing Machine as per ASTM standard. The Micro hardness of the samples was determined using Vickers Micro hardness tester, carried out under a load of $187.5 \mathrm{~N}$ and a dwell time of 5 seconds. Structure revealing machine was used to take micro structural images of the specimens at $40 \mathrm{x}$ magnification. The etching was done using Keller enchant.

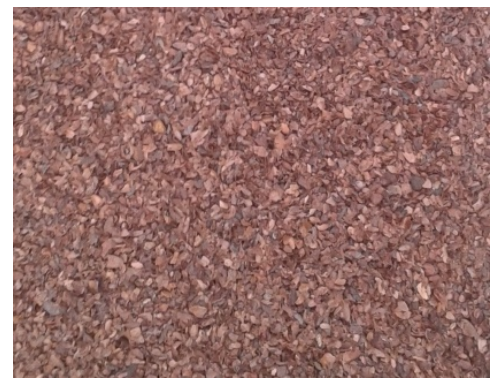

Figure 1. Raw Cocoa Bean Shells (CBS)

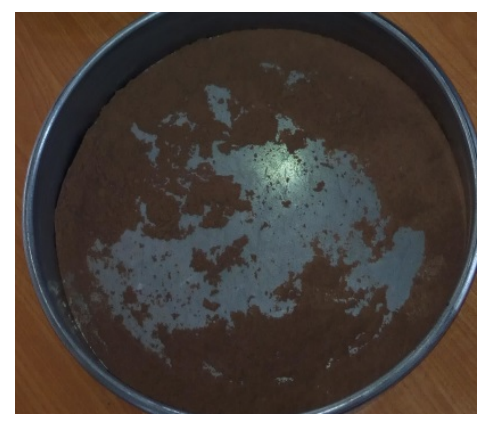

Figure 2. Pulverized Cocoa Bean Shells (150microns)

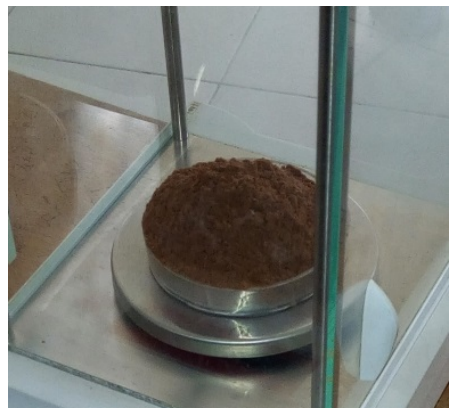

Figure 3. Powdered Cocoa Bean Shells $(225 \mu \mathrm{m})$

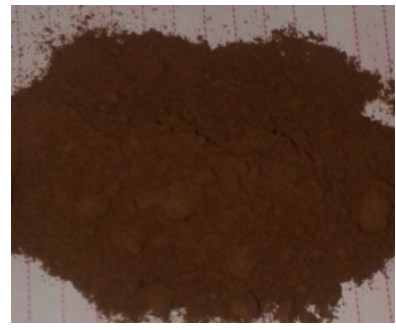

Figure 4. Pulverized CBS $(300 \mu \mathrm{m})$

\subsubsection{Tensile Testing Procedure}

As shown in Figure 5, each of the test specimens was specified to have $70 \mathrm{~mm}$ gauge length on the tensile test specimen using the dial callipers and marker. Then the thickness and width of the specimens was re-checked using the dial callipers. The 
specimen was placed on the machine grips and removed the slack by moving the lower crosshead. The load indicator was set at zero and the right side hydraulic valve was opened about halve turn. Load was applied increasingly at a slow rate. Strain value started to increase more rapidly as the load was continuously applied on the sample until it fractured. The load at failure was read from the load indicator and recorded. Using the dial callipers, the dimensions of the final gauge length, thickness and width was obtained and recorded.
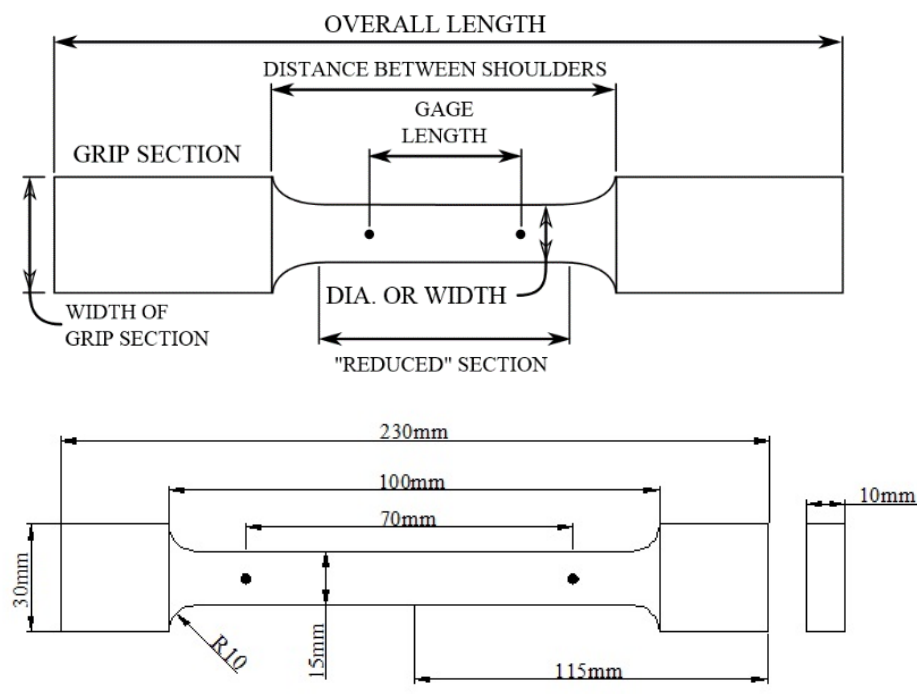

Figure 5. Tensile Test Specimen Specification

\subsubsection{Microstructural Examination Procedure}

The specimen was cut to a hard grip size using hack saw. As shown in the appendix, the specimens were inserted in phenolic resin in order to enable easy manual and automated grinding/polishing operations. After mounting, surface damages created by hacksaw during cutting were removed by grinding operation using emery papers of fineness number in the following increasing order: $150,220,320,400,600,800$ and 1200 respectively. During the process, water was constantly added to reduce friction on the phenolic resin surface and also air-dried with blower immediately after grinding to avoid rust. The fine scratches caused by final grinding operation were removed by mounting the specimen on a polishing machine with a mixture of manganese dioxide $\left(\mathrm{MnO}_{2}\right)$. In other to reveal the microstructural features of the polished specimen, the specimen was etched in $190 \mathrm{ml}$ distilled water, $5 \mathrm{ml}$ Nitric acid, $3 \mathrm{ml}$ hydrochloric acid and $2 \mathrm{ml}$ of hydrofluoric acid for 23 seconds. After etching operation, the specimens were vigorously washed in water and blown immediately before taking them to the metallurgical microscope for inspection. The pictures resulting from inspection was magnified to $40 \times 0.65$ for proper understanding of the micrographs.

\subsubsection{Vicker's Micro Hardness Testing Procedure}

Micro hardness testing is a method of determining a material's hardness or resistance to penetration when test samples www.astesi.com are very small or thin, or when small regions in a composite sample or plating are to be measured. During micro hardness testing, a Vicker's (DPH) diamond indenter is pressed into the mounted specimen's surface with a penetrator and a light load of up to 1000 grams. The result of applying the load with a penetrator is an indentation or permanent deformation of the material surface caused by the shape of the indenter. Accurate measurement of the resulting indentation requires the use of a special micro hardness testing microscope since the indentations are so small. The procedure is pictorially displayed in Figure 6.

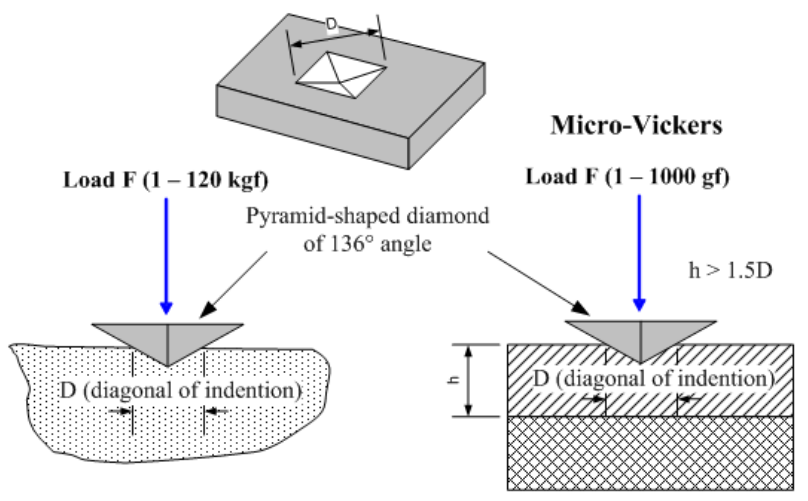

Figure 6. Vicker's Hardness Procedure

\section{Results and Discussion}

\subsection{Tensile Testing Result}

Tensile strength and ductility values are computed from the ultimate tensile testing machine.

The following equations (1) to (6) were used in calculating the tensile strength values

$$
\begin{aligned}
& A R E A=\frac{\pi D^{2}}{4} \\
& M A X . L O A D=R L X R F
\end{aligned}
$$

Where:

$R L=R A M L O A D$

$R M=R A M F A C T O R=6.492$

$$
\begin{aligned}
& U T S=\frac{R L X R F}{A_{O}} \\
& \text { YIELD STRESS }=\frac{U T S}{1.31} \\
& \text { YIELD LOAD }=Y S X A_{O} \\
& \% E=\frac{L_{f}-L_{O}}{L_{O}} \times 100
\end{aligned}
$$

The reading taken from the ultimate tensile testing machine is as presented in Table 4 . 
Adeyemi. I. O. et al. / Advances in Science, Technology and Engineering Systems Journal Vol. 2, No. 4, 14-25 (2017)

Table 4. Tensile Strength Test Data Obtained for all Samples

\begin{tabular}{|c|c|c|c|c|c|c|}
\hline $\begin{array}{l}\text { SAMPL } \\
\text { E }\end{array}$ & $\begin{array}{l}\mathrm{L}_{0} \\
(\mathrm{~mm} \\
)\end{array}$ & $\begin{array}{l}\mathbf{L}_{\mathbf{f}} \\
(\mathrm{mm} \\
)\end{array}$ & $\begin{array}{l}\mathrm{D}_{0} \\
(\mathrm{~mm} \\
)\end{array}$ & $\begin{array}{l}\text { Df }_{\mathrm{f}} \\
\text { (in) }\end{array}$ & $\begin{array}{l}A_{0} \\
\left(i^{2}\right)\end{array}$ & $\begin{array}{l}\text { RAM } \\
\text { LOA } \\
\text { D } \\
\text { (RL) }\end{array}$ \\
\hline $\begin{array}{l}\text { Pure Al } \\
\text { without } \\
\text { inoculant }\end{array}$ & 110 & 122 & 12.0 & 0.47 & $\begin{array}{l}0.17 \\
5\end{array}$ & 1300 \\
\hline $\begin{array}{l}\text { Pure Al } \\
\text { with } \\
150 \mu \mathrm{m} \\
\text { inoculant }\end{array}$ & 110 & 112 & 12.2 & 0.48 & $\begin{array}{l}0.18 \\
1\end{array}$ & 1150 \\
\hline $\begin{array}{l}\text { Pure Al } \\
\text { with } \\
225 \mu \mathrm{m} \\
\text { inoculant }\end{array}$ & 110 & 111 & 12.1 & $\begin{array}{l}0.47 \\
6\end{array}$ & $\begin{array}{l}0.17 \\
8\end{array}$ & 1000 \\
\hline $\begin{array}{l}\text { Pure Al } \\
\text { with } \\
300 \mu \mathrm{m} \\
\text { inoculant }\end{array}$ & 110 & 110.5 & 12.2 & 0.48 & $\begin{array}{l}0.18 \\
1\end{array}$ & 900 \\
\hline
\end{tabular}

The distribution pattern of Ultimate Tensile Strength (UTS), Yield Strength (YS), and percentage Elongation (\%E) of each of the specimens are calculated as follows using equations (1) to (6).

(a) Pure Al without Inoculant

$A R E A=A_{o}=\frac{\pi D^{2}}{4}=0.175 \mathrm{in}^{2}$

$R A M L O A D=R L=1300 \mathrm{lb}$

$R A M F A C T O R=6.492$

$$
\begin{aligned}
& M A X . L O A D=R L X R F=8439.6 \mathbf{l b} \\
& U T S=\frac{R L X R F}{A_{O}}=48226 \mathbf{p s i}
\end{aligned}
$$

$Y I E L D S T R E S S=\frac{U T S}{1.31}=\mathbf{3 6 8 1 4} \boldsymbol{p s i}$

$Y I E L D L O A D=Y S X A_{O}=\mathbf{6 4 4 2} \mathrm{lb}$

$\% E=\frac{L_{f}-L_{o}}{L_{o}} \times 100=\mathbf{1 0 . 9 \%}$

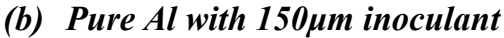

$$
\begin{aligned}
& A R E A=A_{o}=\frac{\pi D^{2}}{4}=0.181 \mathrm{in}^{2} \\
& R A M L O A D=R L=1150 \mathrm{lb}
\end{aligned}
$$

RAM FACTOR $=6.492$

$M A X . L O A D=R L X R F=\mathbf{7 4 6 5 . 8} \mathrm{lb}$

$U T S=\frac{R L X R F}{A_{O}}=\mathbf{4 1 2 4 7 . 6} \mathbf{p s i}$

$Y I E L D S T R E S S=\frac{U T S}{1.31}=\mathbf{3 1 4 8 6 . 7} \mathbf{p s i}$

$Y I E L D L O A D=Y S X A_{O}=\mathbf{5 6 9 9} \mathbf{l b}$

$\% E=\frac{L_{f}-L_{o}}{L_{o}} \times 100=\mathbf{1 . 8 2 \%}$

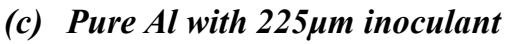

$$
\begin{aligned}
& A R E A=A_{O}=\frac{\pi D^{2}}{4}=0.178 \mathrm{in}^{2} \\
& R A M L O A D=R L=1000 \mathrm{lb} \\
& R A M F A C T O R=6.492 \\
& M A X . L O A D=R L X R F=\mathbf{6 4 9 2} \mathrm{lb} \\
& U T S=\frac{R L X R F}{A_{O}}=\mathbf{3 6 4 7 2} \mathbf{p s i} \\
& Y I E L D S T R E S S=\frac{U T S}{1.31}=\mathbf{2 7 8 4 1} \mathbf{p s i} \\
& Y I E L D L O A D=Y S X A_{O}=\mathbf{4 9 5 6} \mathbf{l b} \\
& \% E=\frac{L_{f}-L_{O}}{L_{O}} \times 100=\mathbf{0 . 9 1 \%}
\end{aligned}
$$

\section{(d) Pure Al with $300 \mu m$ inoculant}

$$
\begin{aligned}
& A R E A=A_{o}=\frac{\pi D^{2}}{4}=0.181 \mathrm{in}^{2} \\
& R A M L O A D=R L=900 \mathrm{lb} \\
& R A M F A C T O R=6.492 \\
& M A X . L O A D=R L X R F=\mathbf{5 8 4 2 . 8} \mathrm{lb} \\
& U T S=\frac{R L X R F}{A_{O}}=\mathbf{3 2 2 8 0 . 7} \mathbf{p s i} \\
& Y I E L D S T R E S S=\frac{U T S}{1.31}=\mathbf{2 4 6 4 1 . 7} \mathbf{p s i} \\
& Y I E L D L O A D=Y S X A_{O}=\mathbf{4 4 6 0} \mathbf{l b} \\
& \% E=\frac{L_{f}-L_{O}}{L_{O}} x 100=\mathbf{0 . 4 5 \%}
\end{aligned}
$$

The above results for each specimen are converted to S. I. unit and summarized as presented below in Table 5 . 
Adeyemi. I. O. et al. / Advances in Science, Technology and Engineering Systems Journal Vol. 2, No. 4, 14-25 (2017)

Table 5. Summary of the calculated Tensile Strength and Ductility Values (converted) of each specimen.

\begin{tabular}{|l|c|c|c|c|}
\hline Sample & $\begin{array}{c}\text { UTS } \\
\left(\mathbf{N} / \mathbf{m m}^{2}\right)\end{array}$ & $\begin{array}{c}\text { YIELD } \\
\text { STRESS } \\
\left(\mathbf{N} / \mathbf{m m}^{2}\right)\end{array}$ & $\begin{array}{c}\text { YIELD } \\
\text { LOAD (N) }\end{array}$ & $\% \mathbf{E}$ \\
\hline $\begin{array}{l}\text { Pure Al } \\
\text { without } \\
\text { inocula } \\
\text { nt }\end{array}$ & 333 & 253 & 28655 & 10.9 \\
\hline $\begin{array}{l}\text { Pure Al } \\
\text { with } \\
\begin{array}{l}150 \mu \mathrm{m} \\
\text { inocula } \\
\text { nt }\end{array}\end{array}$ & 284 & 217 & 25350 & 1.82 \\
\hline $\begin{array}{l}\text { Pure Al } \\
\text { with } \\
225 \mu \mathrm{m} \\
\text { inocula } \\
\text { nt }\end{array}$ & 251 & 192 & 22045 & 0.91 \\
\hline $\begin{array}{l}\text { Pure Al } \\
\text { with } \\
300 \mu \mathrm{m} \\
\text { inocula } \\
\text { nt }\end{array}$ & 223 & 170 & 19839 & 0.45 \\
\hline
\end{tabular}

\section{Note in table 4 that:}

$\begin{array}{lll}\mathrm{D}_{\mathrm{o}} & = & \text { Initial Diameter } \\ \mathrm{D}_{\mathrm{f}} & = & \text { Final Diameter } \\ \mathrm{A}_{\mathrm{o}} & = & \text { Initial Area } \\ \mathrm{L}_{\mathrm{o}} & = & \text { Original Length } \\ \mathrm{L}_{\mathrm{f}} & = & \text { Final Length } \\ \mathrm{E} & = & \text { Elongation }\end{array}$

From Table 5 above, it is shown that the tensile strength of the specimen diminishes as the grain size of the inoculant increases. This may be as a result of increased fine crystals of aluminium. Finer crystals lead to reduced tensile strength but increased compressive strength [17]. Reduced elongation (E) is also an indication of declining ductility of the metal. Ordinarily, the presence of copper in pure aluminium is to improve the strength and machinability, but other elements such as Calcium, Phosphorous, Potassium, and sodium present with it in the inoculant might have inhibited its effect on the aluminium [17].

\subsection{Metallographic Test Result and Analysis}

Figures 7, 8, 9 and 10 show the microstructures of the inoculated aluminium. It is obvious from the figure that the microstructure consists of two distinguished phases - a dark and a bright white phase. The rough surface was not actually from the specimen preparation but from the way the material was cast.

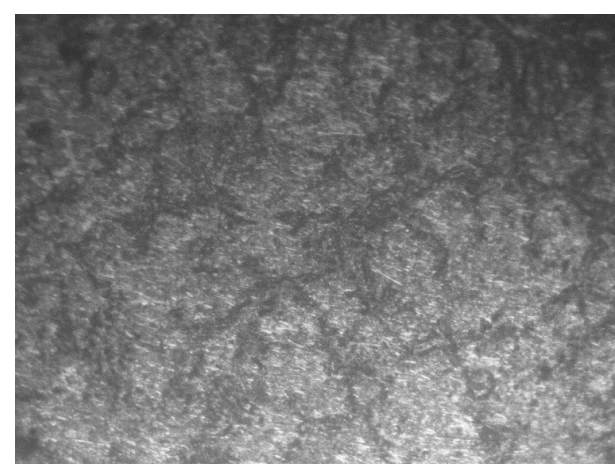

Figure 7. Pure Al sample without inoculant at $\times 40$ Magnification

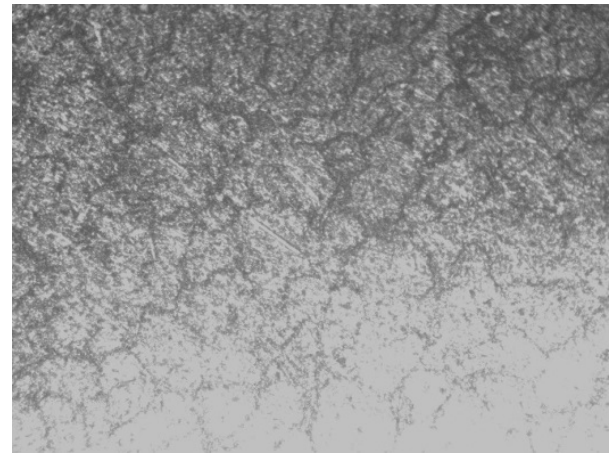

Figure 8. Pure Al sample with $150 \mu \mathrm{m}$ inoculant at $\times 40$ Magnification

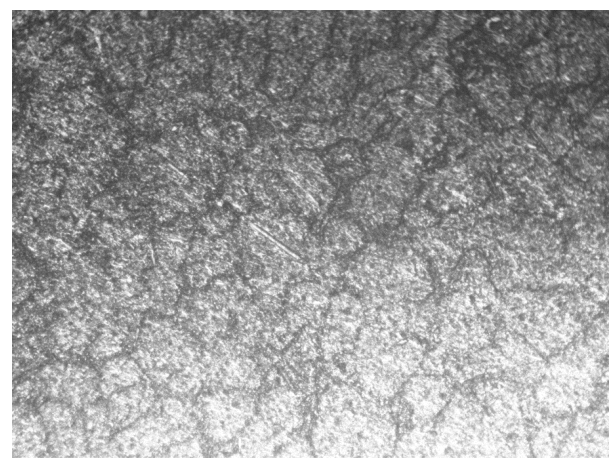

Figure 9. Pure Al sample with $225 \mu \mathrm{m}$ inoculant at $\times 40$ Magnification

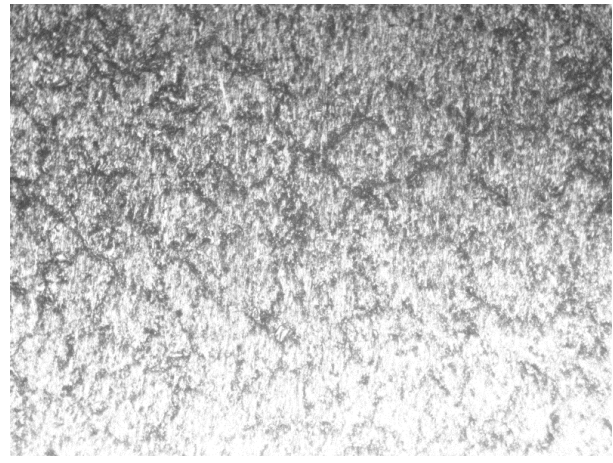

Figure 10. Pure Al sample with $300 \mu \mathrm{m}$ inoculant at $\times 40$ Magnification 
It is seen from the microstructural examination as depicted in figures 7 to 10 that addition of inoculant introduced whitish phase in the microstructure, and it became more pronounced as the grain size of the inoculant increased in the metal matrix. Also the aluminium crystals appear finer in succession. This is responsible for lower tensile strength and higher compressive strength.

\subsection{Vicker's Micro Hardness Result}

From the appendix (Figures 4 to 7 ) the results and pictures from the Vicker's hardness test are presented. It indicated that the increasing grain size of the inoculant added to the pure aluminium increases the micro hardness of the material. After conducting the Vicker's hardness test at different point on the samples, the specimen with no inoculant addition (the control sample) has an average hardness value of $29 \mathrm{HB}$. While each pure Al sample with inoculant having $150 \mu \mathrm{m}, 225 \mu \mathrm{m}$, and $300 \mu \mathrm{m}$ grain has an average hardness value of $56 \mathrm{HB}, 61 \mathrm{HB}$, and $72 \mathrm{HB}$ respectively.

\section{Conclusion}

In this work, the effects of varying the grains size of the selected agro-waste based inoculant on some mechanical properties of pure aluminium was studied. The microstructural examination showed that the mechanical properties are dependent on the matrix as the aluminium grains became more refined with increasing grain size of the inoculant. I.e. Due to increasing grain size of the inoculant, the micro hardness increased as the aluminium crystal size became finer. Meanwhile, the tensile strength, and ductility decreased as grain size of the inoculant increased. The overall results showed that the used agro-waste based inoculant has the capability of refining the crystal size of pure aluminium as its grain size increases. This will make the resulting aluminium alloy applicable in areas where hardness is of superior consideration relative to tensile strength.

\section{Conflict of Interest}

The authors have no conflict of interest.

\section{Acknowledgment}

The authors appreciate all the personalities that contributed in one way or the other towards the breakthrough of this work.

\section{References}

[1] A. I. O. Zaid, A. I. O.,"Review of the Grain Refinement of Aluminum and its Alloys" Proceedings of the International Symposium on Advanced Materials, ISAM, Islamabad, Pakistan, 2001.

[2] J. Szajnar, M. Stawarz, and T. Wrobel, "Inoculation of Pure Aluminium Structure with Ti+B Addition in Impulse Magnetic Field," Journal of Achievements in Materials and Manufacturing Engineering, 14: 64-69, 2006.

[3] ASM International, "Casting" in Metals Handbook, vol. 15 of The ASM Handbook, ASM International, Geauga County, Ohio, USA, 9th edition, 1992.

[4] O. S. I. Fayomi, A. P. I. Popoola, F. Oyawale, O. O. Ajayi, "Performance Evaluation and Multi-doped Composite Conditioned of A5-type/10\%Ti-Sn
Alloy: Processing and Properties". J Fail. Anal. \& Preven. ASM International. DOI 10.1007/s11668-015-0058-x. (16): 135-141, 2016.

[5] D. VanderBoon, "Effects of Solidification Rates on Porosity Formation and Cast Microstructure in Aluminum Alloy A356. Laboratory Module 3, Grand Valley State University, 1-5, 2005.

[6] AZO Materials, "Aluminium - Specifications, Properties, Classifications and Applications". Retrieved from: www.azom.com/article.aspx, 2017.

[7] O. O. Ajibola, and D. T. Oloruntoba, "Effect of MgFeSi Inoculant on Properties of Cast 6061 Al Alloy for Brake Master Piston Application". Indian Journal of Materials Science. Retrieved from: http://dx.doi.org/10.1155/2015/756219, Volume 2015, Article ID 756219, 10 pages, 2015

[8] M. Bedel, L. Heyvaert, M. Založnik, H. Combeau, D. Daloz and G. Lesoult. "Process-Scale Modelling of Microstructure in Direct Chill Casting of Aluminium Alloys". IOP Conf. Series: Materials Science and Engineering. 012100 doi:10.1088/1757-899X/84/1/012100: 84 (2015).

[9] Qian Wang, Chunxiang Cui, Xin Wang, Lichen Zhao, Nuo Li and Shuiqing Liu, "Effect of Preparation Parameter on Microstructure and Grain Refining Behavior of In Situ AlN-TiN-TiB2/Al Composite Inoculants on Pure Aluminum". Journal of Metals, doi: 10.3390/met7020056. Retrieved from: www.mdpi.com/journal/metals 7: 56, 2017

[10] A. L. Greer, "Grain Refinement of Alloys by Inoculation of Melt. Phil. Trans. R. Soc. Lond. A, 361: 479-495, 2003.

[11] D. Wearing, A. P. Horsfield, W. W. Xu, P. D. Lee, "Which wets TiB2 inoculant particles: Al or Al3Ti?” J. Alloy. Compd., 664: 460-468, 2016.

[12] H. L. Zhao, Y. Song, M. Li, S. K. Guan, "Grain Refining Efficiency and Microstructure of Al-Ti-C-RE Master Alloy". J. Alloy. Compd., 508: 206$211,2010$.

[13] B. K. G. Marcel, K. B. Andre, D. Theodore, and K. C. Seraphin, "Waste and By-products of Cocoa in Breeding Research Synthesis". International Journal of Agronomy and Agricultural Research (IJAAR), 2011.

[14] Feedipedia, "Cocoa (Theobroma Cacao) Beans and by-product. Retrieved from www.feedipedia.org, 2010.

[15] FAO, “Animal Feed Resources Information System”, FAO, 1992 - 2002

[16] Adeyemi Ibukun Olabisi., Ademoh Nuhu. Adam, Okwu Modestus Okechukwu, "Development and Assessment of Composite Brake Pad Using Pulverized Cocoa Beans Shells Filler". International Journal of Materials Science and Applications. doi: 10.11648/j.ijmsa.20160502.16. 5(2): 66-78, 2016

[17] R. S. Khurmi, and J. K. Gupta, "A Text Book of Workshop Technology (Manufacturing Processes) '. S. Chand \& Company Ltd. Reprinted edition: 18 $-18 \& 117-120,2004$ 
Appendix

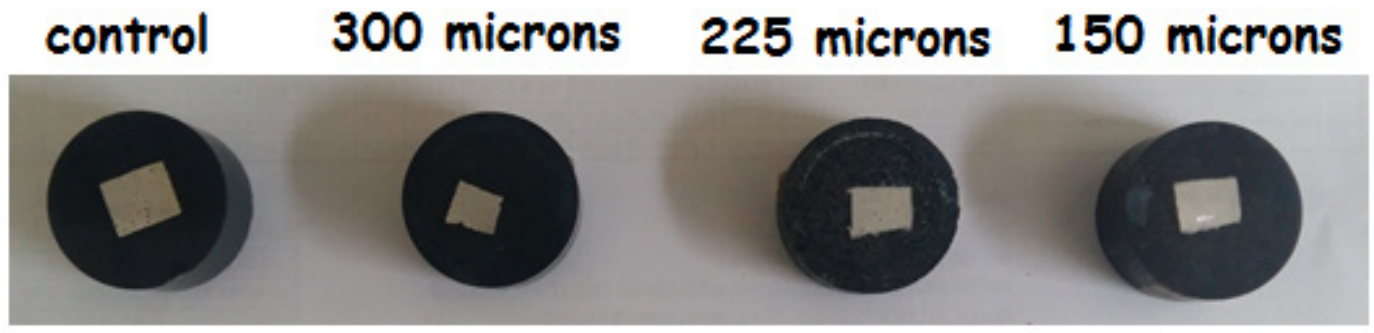

Figure 1. Mounted Microstructural Test Specimens

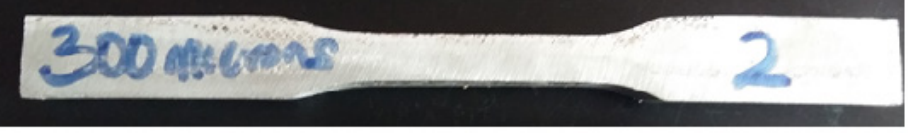

300 microns sample before fracture

\section{5 mecosos}

225 microns sample before fracture

\section{0 micions}

150 microns sample before fracture

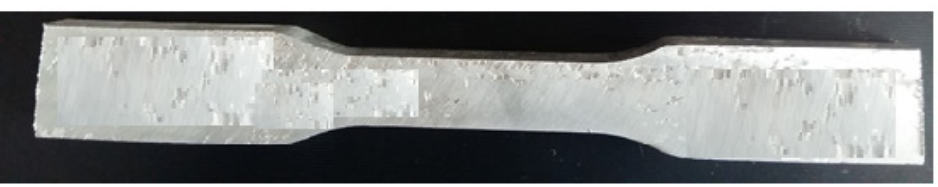

Control sample before fracture

Figure 2. Tensile Strength Specimens before Fracture.

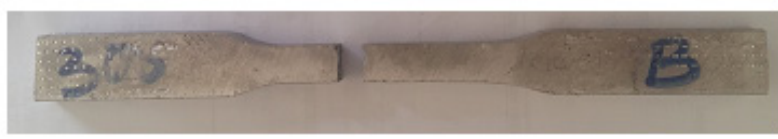

300 microns Sample after fracture

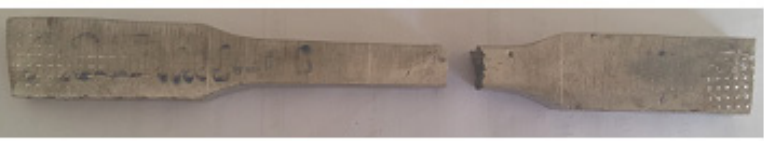

225 microns Sample after fracture

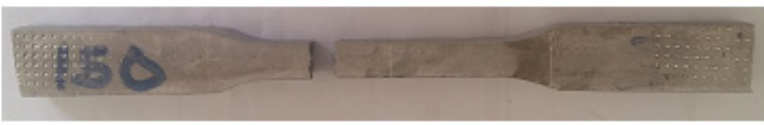

150 microns Sample after fracture

Control Sample after fracture

Figure 3. Tensile Strength Specimens after Fracture. 
CONTROL SAMPLE VICKER HARDNESS

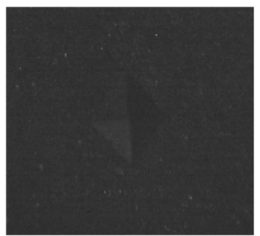

lst Indent

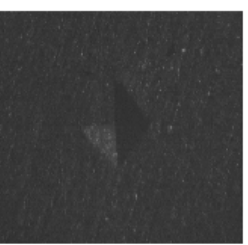

6th Indent

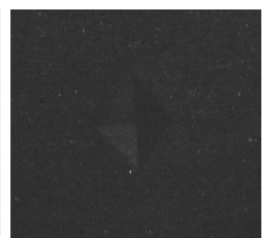

2nd Indent

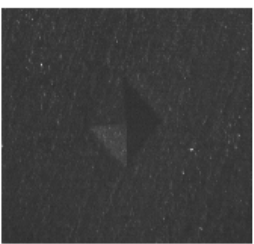

7 th Indent

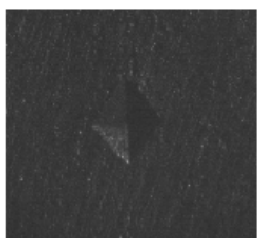

3rd Indent

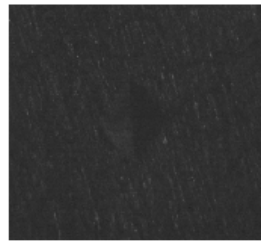

8th Indent

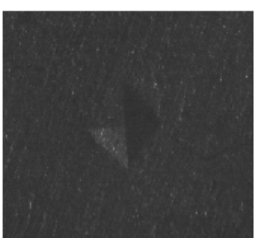

4th Indent

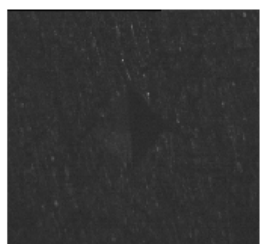

9th Indent

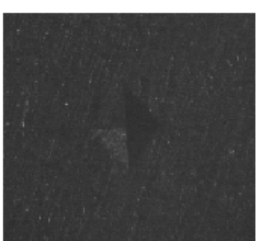

5th Indent

Measurement Line Duramin-5

Date :04/01/2017

Time : 03:44:33

Information : Control Sample

Limit [H] : 550.0 Case Depth : ***

\begin{tabular}{|r|r|r|r|r|l|l|l|}
\hline $\mathrm{X}[\mathrm{mm}]$ & $\mathrm{Y}[\mathrm{mm}]$ & $\mathrm{D} 1[\mathrm{~m}]$ & $\mathrm{D} 2[\mathrm{~m}]$ & Hardness & Force & Time $(\mathrm{s})$ & Lens \\
\hline 0.000 & 0.000 & 354.9 & 347.1 & 30.1 & 2000.0 & 5.0 & 10.0 \\
\hline 0.000 & 0.000 & 361.7 & 335.8 & 30.5 & 2000.0 & 5.0 & 10.0 \\
\hline 0.000 & 0.000 & 380.9 & 335.8 & 28.9 & 2000.0 & 5.0 & 10.0 \\
\hline 0.000 & 0.000 & 380.9 & 340.3 & 28.5 & 2000.0 & 5.0 & 10.0 \\
\hline 0.000 & 0.000 & 380.9 & 330.2 & 29.3 & 2000.0 & 5.0 & 10.0 \\
\hline 0.000 & 0.000 & 374.1 & 330.2 & 29.9 & 2000.0 & 5.0 & 10.0 \\
\hline 0.000 & 0.000 & 384.3 & 341.5 & 28.2 & 2000.0 & 5.0 & 10.0 \\
\hline 0.000 & 0.000 & 384.3 & 346.0 & 27.8 & 2000.0 & 5.0 & 10.0 \\
\hline 0.000 & 0.000 & 384.3 & 339.2 & 28.3 & 2000.0 & 5.0 & 10.0 \\
\hline 0.000 & 0.000 & 378.6 & 339.2 & 28.8 & 2000.0 & 5.0 & 10.0 \\
\hline
\end{tabular}

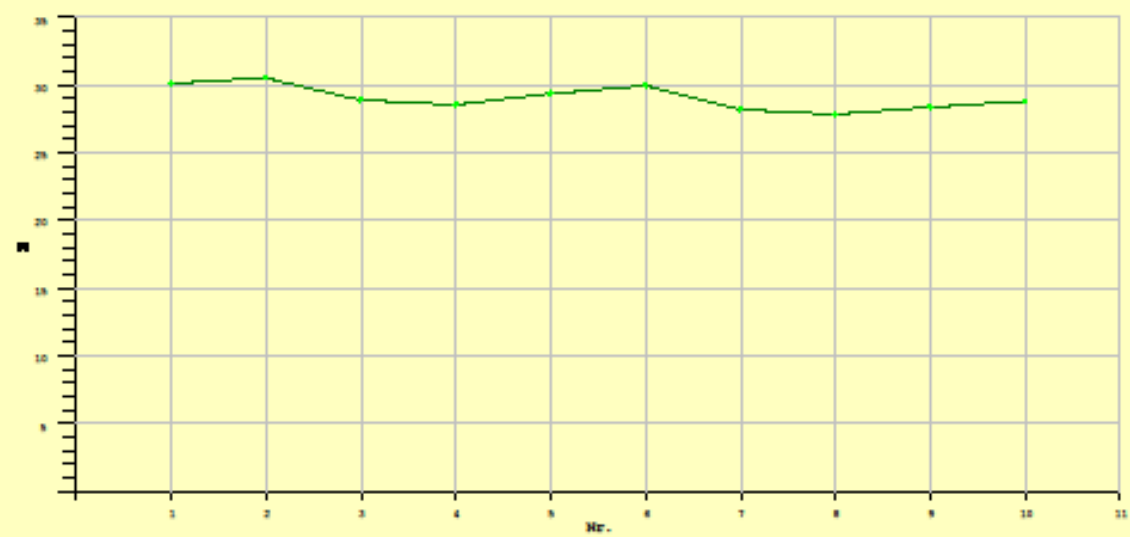

- Page 1 -

Figure 4. Vicker's Hardness Results of Non-inoculated aluminium Specimen 
150 microns SAMPLE VICKER HARDNESS

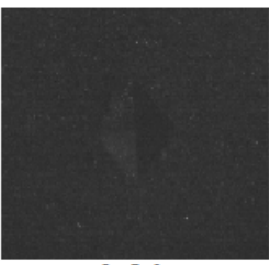

lst Indent

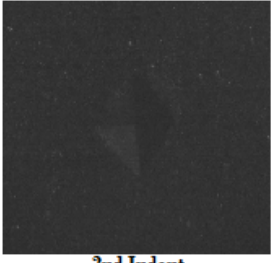

2nd Indent

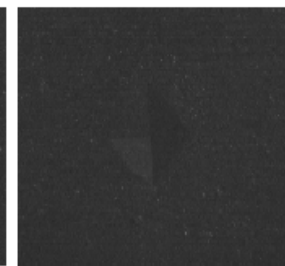

6th Indent

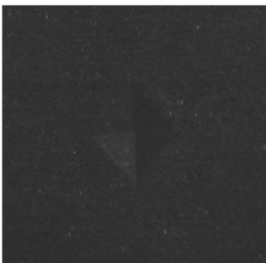

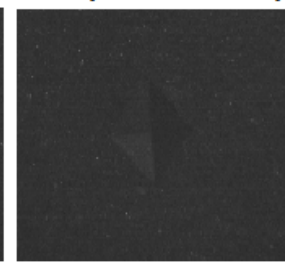

3rd Indent

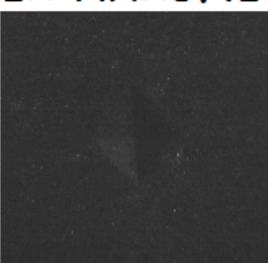

4th Indent

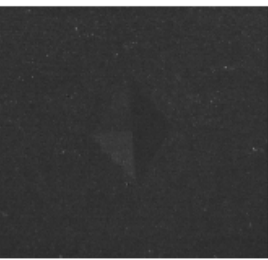

5th Indent

\section{Measurement Line Duramin-5}

Date :04/01/2017

Time : 01:28:50

Information : 150 microns Sample

Limit $[\mathrm{H}]: 550.0$ Case Depth : ***

\begin{tabular}{|r|r|r|r|r|l|l|l|}
\hline $\mathrm{X}[\mathrm{mm}]$ & $\mathrm{Y}[\mathrm{mm}]$ & D1 $[\mu \mathrm{m}]$ & D2 $[\mu \mathrm{m}]$ & Hardness & Force & Time $(\mathbf{s})$ & Lens \\
\hline 0.000 & 0.000 & 241.9 & 263.4 & 58.1 & 2000.0 & 5.0 & 10.0 \\
\hline 0.000 & 0.000 & 248.6 & 263.4 & 56.6 & 2000.0 & 5.0 & 10.0 \\
\hline 0.000 & 0.000 & 249.8 & 263.4 & 56.3 & 2000.0 & 5.0 & 10.0 \\
\hline 0.000 & 0.000 & 247.5 & 265.7 & 56.3 & 2000.0 & 5.0 & 10.0 \\
\hline 0.000 & 0.000 & 257.7 & 254.4 & 56.6 & 2000.0 & 5.0 & 10.0 \\
\hline 0.000 & 0.000 & 262.2 & 248.7 & 56.8 & 2000.0 & 5.0 & 10.0 \\
\hline 0.000 & 0.000 & 253.2 & 261.2 & 56.1 & 2000.0 & 5.0 & 10.0 \\
\hline
\end{tabular}

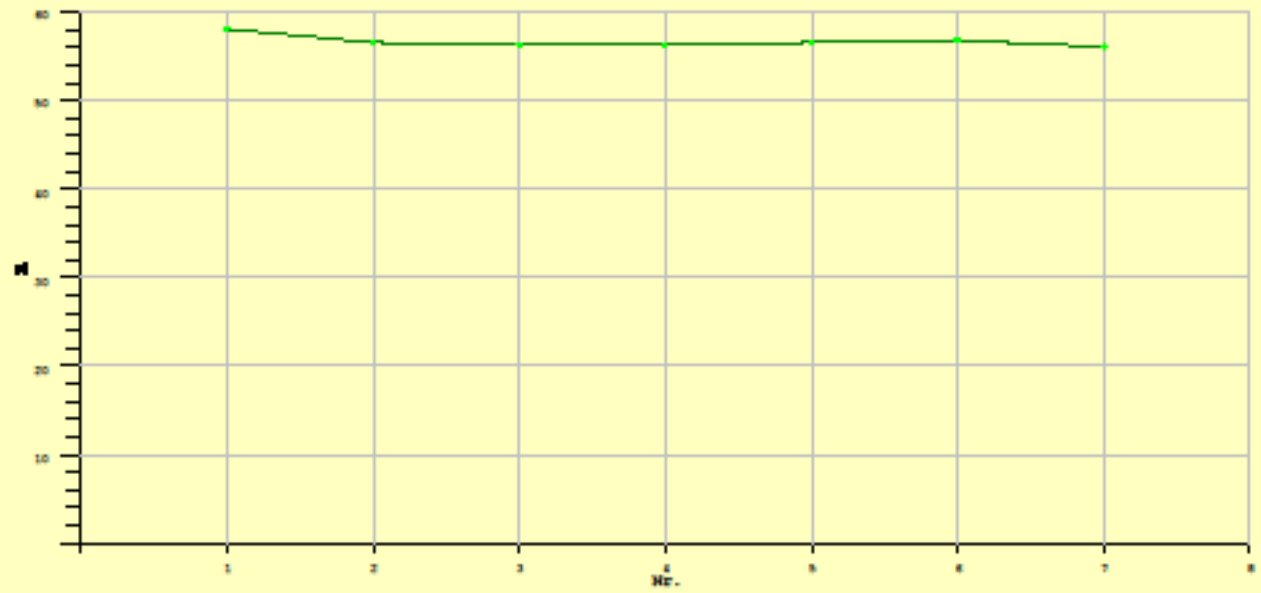

- Page 1 -

Figure 5. Vicker's Hardness Results of aluminium Specimen with $150 \mu \mathrm{m}$ grain size of the inoculant 
225 microns SAMPLE VICKER HARDNESS

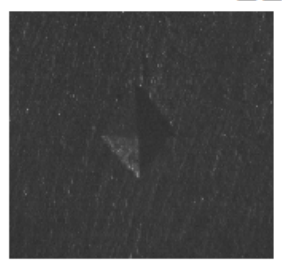

lst Indent

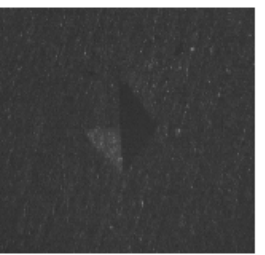

6th Indent

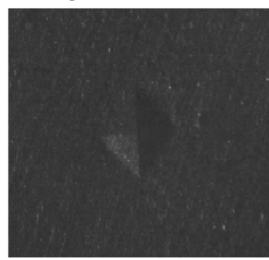

2nd Indent

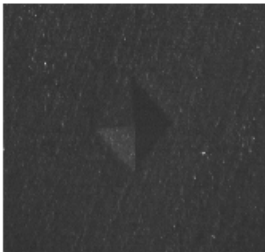

7th Indent

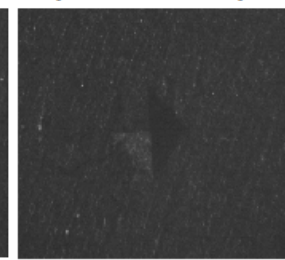

3rd Indent

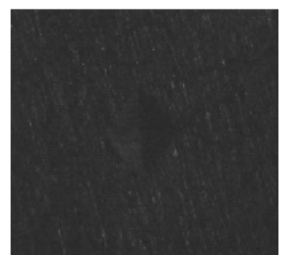

8th Indent

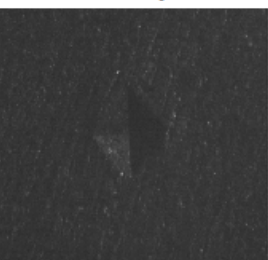

4th Indent

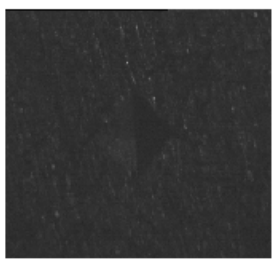

9th Indent

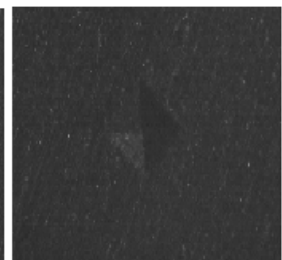

5th Indent

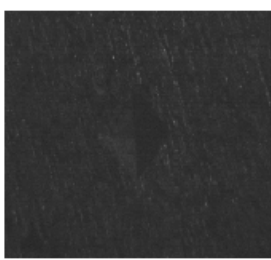

10th Indent

Measurement Line Duramin-5

Date :04/01/2017

Time : 02:36:59

Information : 225microns Sample

Limit $[\mathrm{H}]: 550.0$ Case Depth : ***

\begin{tabular}{|r|r|r|r|r|l|l|l|}
\hline$X[\mathrm{~mm}]$ & $Y[\mathrm{~mm}]$ & D1 [um] & D2 [um] & Hardness & Force & Time $(\mathrm{s})$ & Lens \\
\hline 0.000 & 0.000 & 243.0 & 248.7 & 61.4 & 2000.0 & 5.0 & 10.0 \\
\hline 0.000 & 0.000 & 254.3 & 243.1 & 60.0 & 2000.0 & 5.0 & 10.0 \\
\hline 0.000 & 0.000 & 244.1 & 247.6 & 61.4 & 2000.0 & 5.0 & 10.0 \\
\hline 0.000 & 0.000 & 243.0 & 245.4 & 62.2 & 2000.0 & 5.0 & 10.0 \\
\hline 0.000 & 0.000 & 243.0 & 254.4 & 60.0 & 2000.0 & 5.0 & 10.0 \\
\hline 0.000 & 0.000 & 239.6 & 251.0 & 61.6 & 2000.0 & 5.0 & 10.0 \\
\hline 0.000 & 0.000 & 240.7 & 245.4 & 62.8 & 2000.0 & 5.0 & 10.0 \\
\hline 0.000 & 0.000 & 241.9 & 246.5 & 62.2 & 2000.0 & 5.0 & 10.0 \\
\hline 0.000 & 0.000 & 247.5 & 249.9 & 60.0 & 2000.0 & 5.0 & 10.0 \\
\hline 0.000 & 0.000 & 247.5 & 243.1 & 61.6 & 2000.0 & 5.0 & 10.0 \\
\hline
\end{tabular}

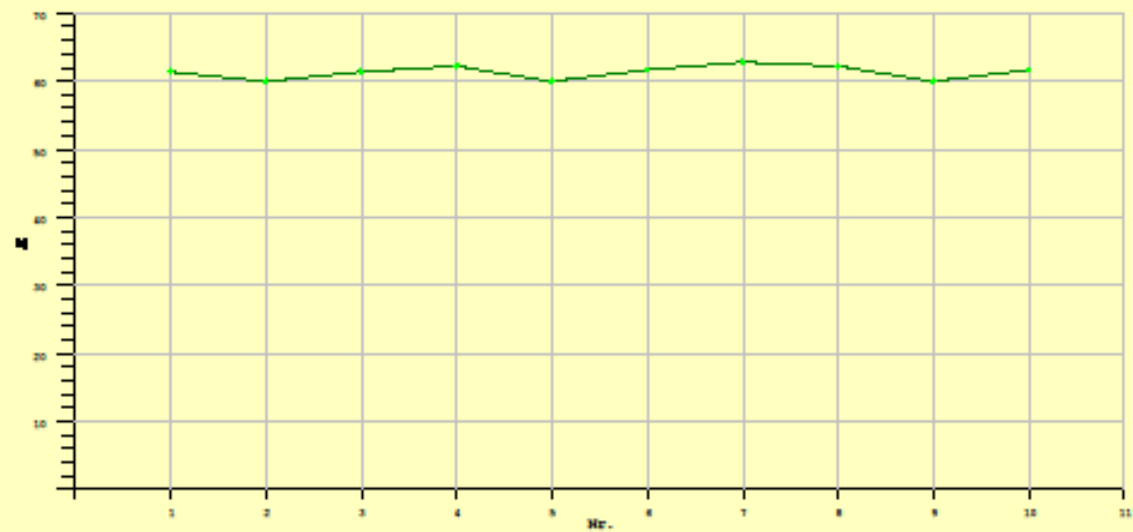

- Page 1 -

Figure 6. Vicker's Hardness Results of aluminium Specimen with $225 \mu \mathrm{m}$ grain size of the inoculant 


\section{0 microns SAMPLE VICKER HARDNESS}

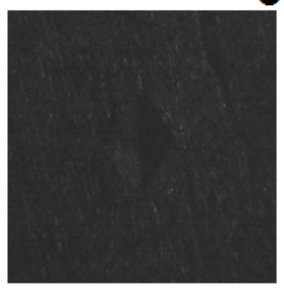

1st Indent

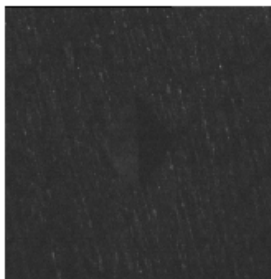

6th Indent

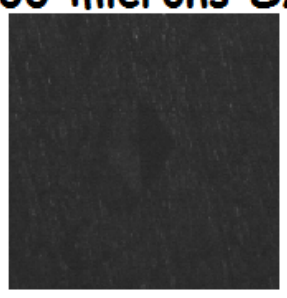

2nd Indent

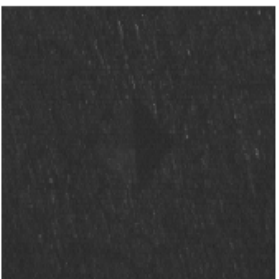

7th Indent

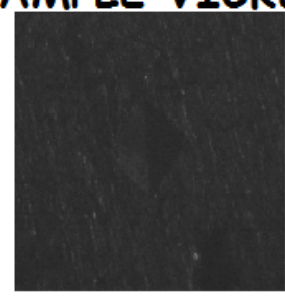

3rd Indent

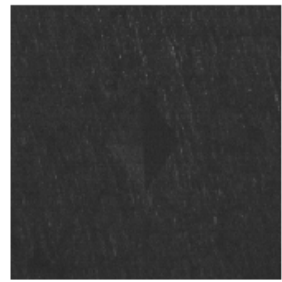

8th Indent

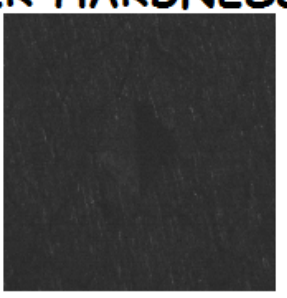

4th Indent

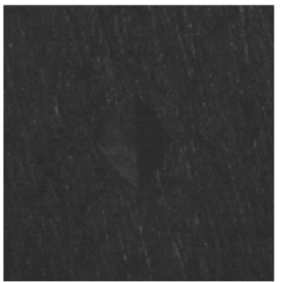

9th Indent

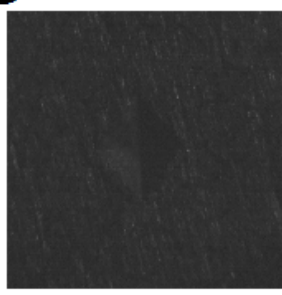

5th Indent

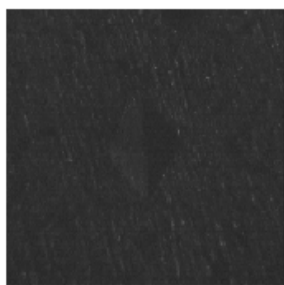

10th Indent

Measurement Line Duramin-5

Date :04/01/2017

Time : 22:26:15

Information : 300microns Sample

Limit $[\mathrm{H}]$ : 550.0 Case Depth : ***

\begin{tabular}{|r|r|r|r|r|l|l|l|}
\hline$X[\mathrm{~mm}]$ & $\mathrm{Y}[\mathrm{mm}]$ & D1 [um] & D2 [um] & Hardness & Force & Time $(\mathbf{s})$ & Lens \\
\hline 0.000 & 0.000 & 221.5 & 230.7 & 72.6 & 2000.0 & 5.0 & 10.0 \\
\hline 0.000 & 0.000 & 224.9 & 227.3 & 72.6 & 2000.0 & 5.0 & 10.0 \\
\hline 0.000 & 0.000 & 230.6 & 226.1 & 71.1 & 2000.0 & 5.0 & 10.0 \\
\hline 0.000 & 0.000 & 220.4 & 226.1 & 74.4 & 2000.0 & 5.0 & 10.0 \\
\hline 0.000 & 0.000 & 226.0 & 227.3 & 72.2 & 2000.0 & 5.0 & 10.0 \\
\hline 0.000 & 0.000 & 226.0 & 225.0 & 72.9 & 2000.0 & 5.0 & 10.0 \\
\hline 0.000 & 0.000 & 228.3 & 223.9 & 72.6 & 2000.0 & 5.0 & 10.0 \\
\hline 0.000 & 0.000 & 226.0 & 223.9 & 73.3 & 2000.0 & 5.0 & 10.0 \\
\hline 0.000 & 0.000 & 228.3 & 223.9 & 72.6 & 2000.0 & 5.0 & 10.0 \\
\hline 0.000 & 0.000 & 229.4 & 223.9 & 72.2 & 2000.0 & 5.0 & 10.0 \\
\hline
\end{tabular}

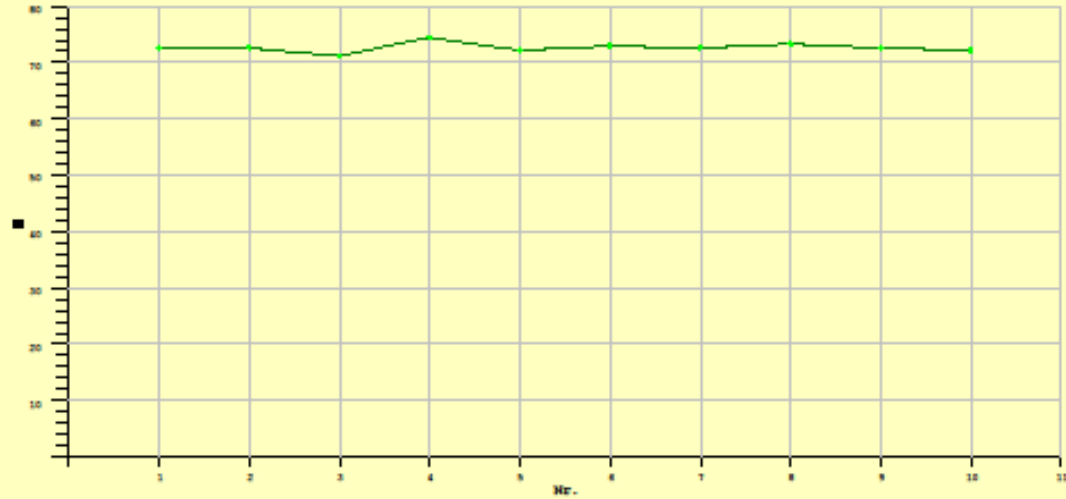

- Page 1 -

Figure 7. Vicker's Hardness Results of aluminium Specimen with $225 \mu \mathrm{m}$ grain size of the inoculant 